Article

\title{
An Optimised Approach of Protecting and Sustaining Large Vehicle System
}

\author{
Adil Saeed *, Zulfiqar A. Khan and Main H. Nazir
}

Received: 5 October 2015; Accepted: 7 December 2015; Published: 11 December 2015

Academic Editor: Muge Mukaddes Darwish

NanoCorr, Energy \& Modelling Research Group, Bournemouth University, Dorset BH12 5BB, UK;

zkhan@bournemouth.ac.uk (Z.A.K.); hnazir@bournemouth.ac.uk (M.H.N.)

* Correspondence: asaeed@bournemouth.ac.uk; Tel.: +44-(0)-1202-965732

\begin{abstract}
This article is a synopsis of our research and highlights the outcomes and its impact. It was conducted for the development of a sustainable approach to protect and sustain large vehicles in sheltered environment for their enhanced longevity. In this research, various modes of failures linked directly or indirectly to the structural ageing of large vehicles were identified, measured, and analysed. Based upon the research conducted, a frame-work with an objective to prolong the structural longevity cost effectively and to retard structural failures has been proposed.
\end{abstract}

Keywords: sustainable; corrosion; large vehicle; paint system

\section{Introduction}

In this article, the term large vehicles refers to military tanks, one such example is shown in Figure 1, and only considers research conducted on such vehicles. These large vehicles are complex objects with a wide variety of interacting components, materials, designs and are manufactured for a specific life span. However, during and beyond their service life, these vehicles start to endure structural ageing, mainly attributed to materials and component degradation through corrosion and wear.

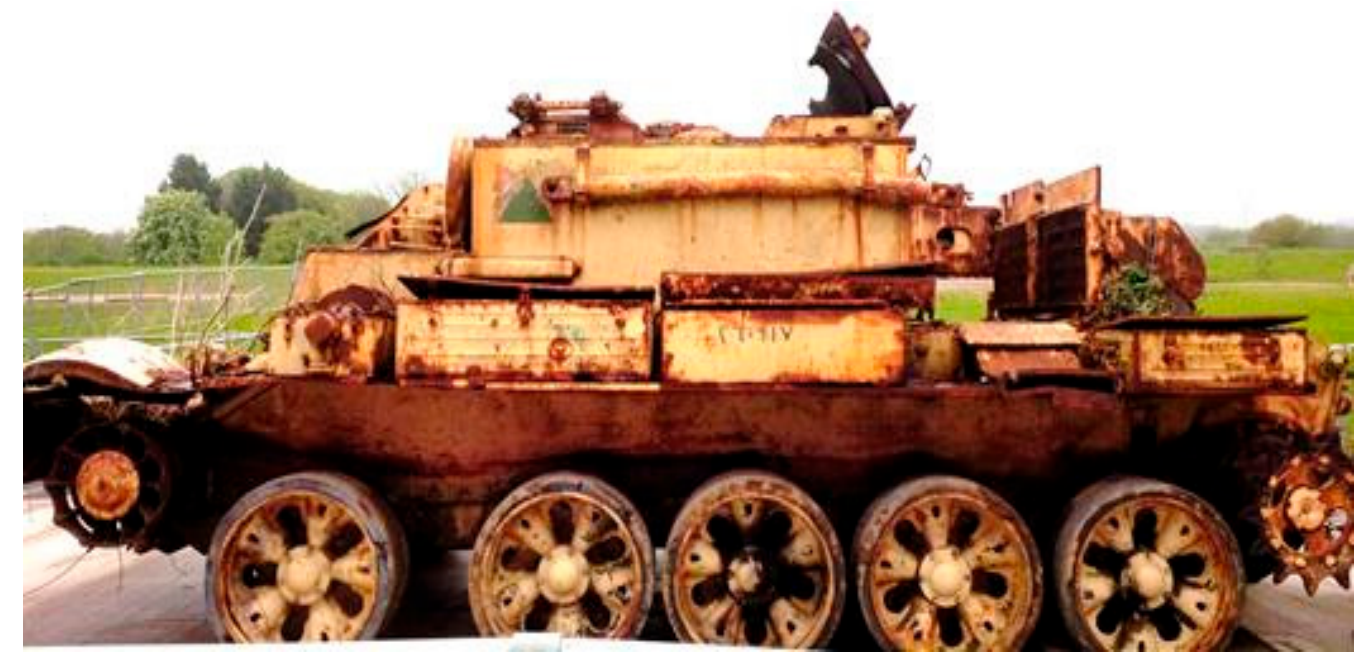

Figure 1. Corrosion damage in Russian T 55 IMR recovery vehicle stationed outside the shelter.

The Tank Museum at Bovington United Kingdom owns a considerable fleet of high-value, large vehicles. These large vehicles were exposed to extreme working and operating conditions 
in battlegrounds during their service life and therefore display structural degradation influenced by corrosion and wear. The exact location and duration of their operation is not known and the information is not documented. Corrosion has a strong impact on these high value vehicles and the development of a framework to protect and sustain these high value vehicles against structural degradation is needed.

This article represents the synopsis of our wider research, which was designed to understand the prevailing failure mechanisms, measure and monitor the identified issues, establish their cause impact, in an effort to achieve an optimised approach to sustaining and protecting large vehicles sustainably and cost effectively beyond their original design life [1-15]. This is the first evidence-based research carried out in this field and is directly linked to the development of a new sustainable sheltered facility incorporating environmental and corrosion condition monitoring systems, to produce further research and research grants.

During the overall project, a five-fold research pattern based on the concept of identifying, measuring, analysing, monitoring and protecting against structural defects was adopted. First, advanced scientific means were utilised for the identification of failures, this was followed by measurement and analysis of failure in materials and paint-systems. Secondly, a framework to monitor the environment and minimise environmental variations (i.e., temperature and relative humidity) was implemented. Third, an in-situ corrosion condition monitoring system has been deployed and useful data are collected. Finally, an empirical model to help design a life expectancy programme and to model materials and paint-system failures for the vehicles stationed in the shelters is proposed.

The five-fold research pattern approach helped to initiate restructuring of the storage, operation and maintenance mechanisms for large vehicles considered in our research.

In this article, some examples of the corrosion damage analysis, component failures, environmental analysis, the initiation and development of an optimised framework for vehicles protection and the research impact are provided. Vehicles presented in this article are stationed in Bovington, United Kingdom.

\section{Research Findings}

In this research, corrosion damage, un-sustainable environmental conditions, paint system failures and component failures were identified as major structural integrity menaces in the large vehicles.

\subsection{Vehicles' Corrosion}

Risks of failures due to corrosion are high and pose significant danger to the structural integrity of large vehicles considered in our research. The magnitude of corrosion is different in every vehicle, which could be the result of their operating environment in different terrains and/or the current environmental/operating conditions. The overwhelming phenomenon of corrosion is shown in Figures 1 and 2. Figure 1 is of a Russian T55 IMR that is stationed outside the shelter and is structurally corroding. Figure 2 shows the severity of the corrosion problem in Togg II, a vehicle stationed inside the shelter. The mechanism of structural degradation was dictated by various modes of corrosion working alone and/or together. In this article, damage due to surface corrosion has been reported briefly. Results of other forms of corrosion, i.e., stress corrosion cracking and pitting, are published elsewhere $[2,4,5]$. 


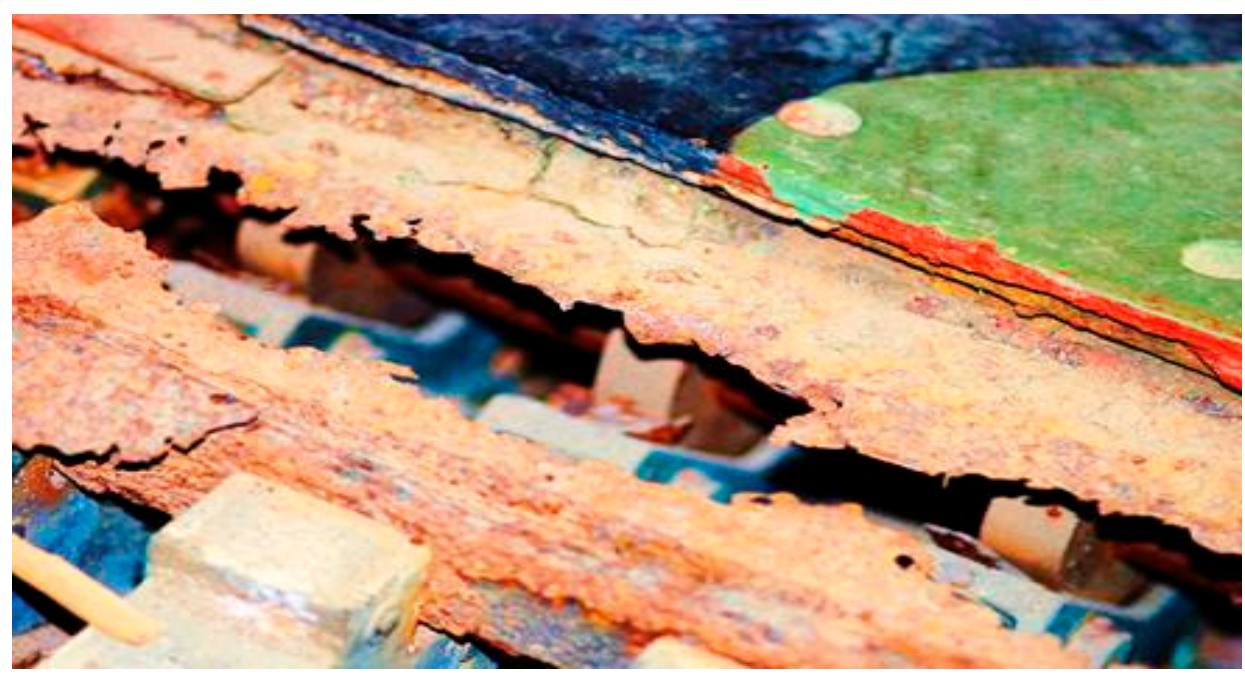

Figure 2. Corrosion damage to Tog II vehicle stationed inside the shelter.

\subsubsection{Corrosion Damage Evaluation}

Surface corrosion damage was evaluated through the advanced surface analysis techniques of ultrasonic scanning. Corrosion surface morphology, and surface contaminants were characterised by using a scanning electron microscopy and an energy dispersive $\mathrm{X}$-ray spectroscopy. In the first phase of the research, six vehicles the, Russian BTR-60, Centaur A27L, Sherman M4A1, Tank Destroyer M10, Tiger 1 and King Tiger, were considered. Results from BT-R 60 are presented here briefly.

Ultrasonic scanning method is a novel technique for measuring the thickness of the metal non-intrusively. An ultrasonic scanning system consists of a transducer, pulser receiver, receiver, transmitter and a display monitor. The system utilises sound waves within the frequency range of 0.1 to $15 \mathrm{MHz}$ rather than radiation. The transducer creates sound waves that travel through the metal which when these waves strike against a defect or the back wall are then reflected back. The reflected sound wave signal is converted into an electrical signal to a display device. In our research, such information were extrapolated to measure the remaining thickness of the metal component $[16,17]$.

Scanning Electron Microscopy (SEM) was used for micro-structural characterisation of the surface and sub-surface defects. To identify surface contaminates on the selected samples, Energy Dispersive X-ray Spectroscopy (EDS) was performed. Both SEM and EDS are advanced and established techniques utilised for the aforementioned analysis.

\subsubsection{Brone-Transporter BTR 60}

Brone-transporter 60 (BTR-60) was manufactured by Gorkovsky Avtomobilny Zavod in the former USSR during 1960-1976. It is one of the most widely used personnel carriers. It remained in production till 1976 [18]. This vehicle was captured during the First Gulf War. This vehicle is parked outside the shelter currently and is exposed to an uncontrolled environment. This vehicle is severely corroding; a sample of the compartment cover was collected for corrosion mapping shown in Figure 3 with the corresponding ultrasonic scan.

Corrosion mapping results of the five lowest and highest remaining thicknesses' are provided in Table 1. A difference of $1 \mathrm{~mm}$ material loss was recorded on the sample selected for the corrosion mapping between the maximum and minimum remaining thicknesses. A consistent decrease in the component thickness was observed.

The purpose behind measuring material loss due to corrosion in five vehicles was to obtain a benchmark. Results showed considerable material loss due to corrosion in all samples collected from the vehicles. The benchmark of the remaining thicknesses will help draw an empirical 
model to predict the life expectancy programme for the vehicles inside the shelters under specific environmental conditions.

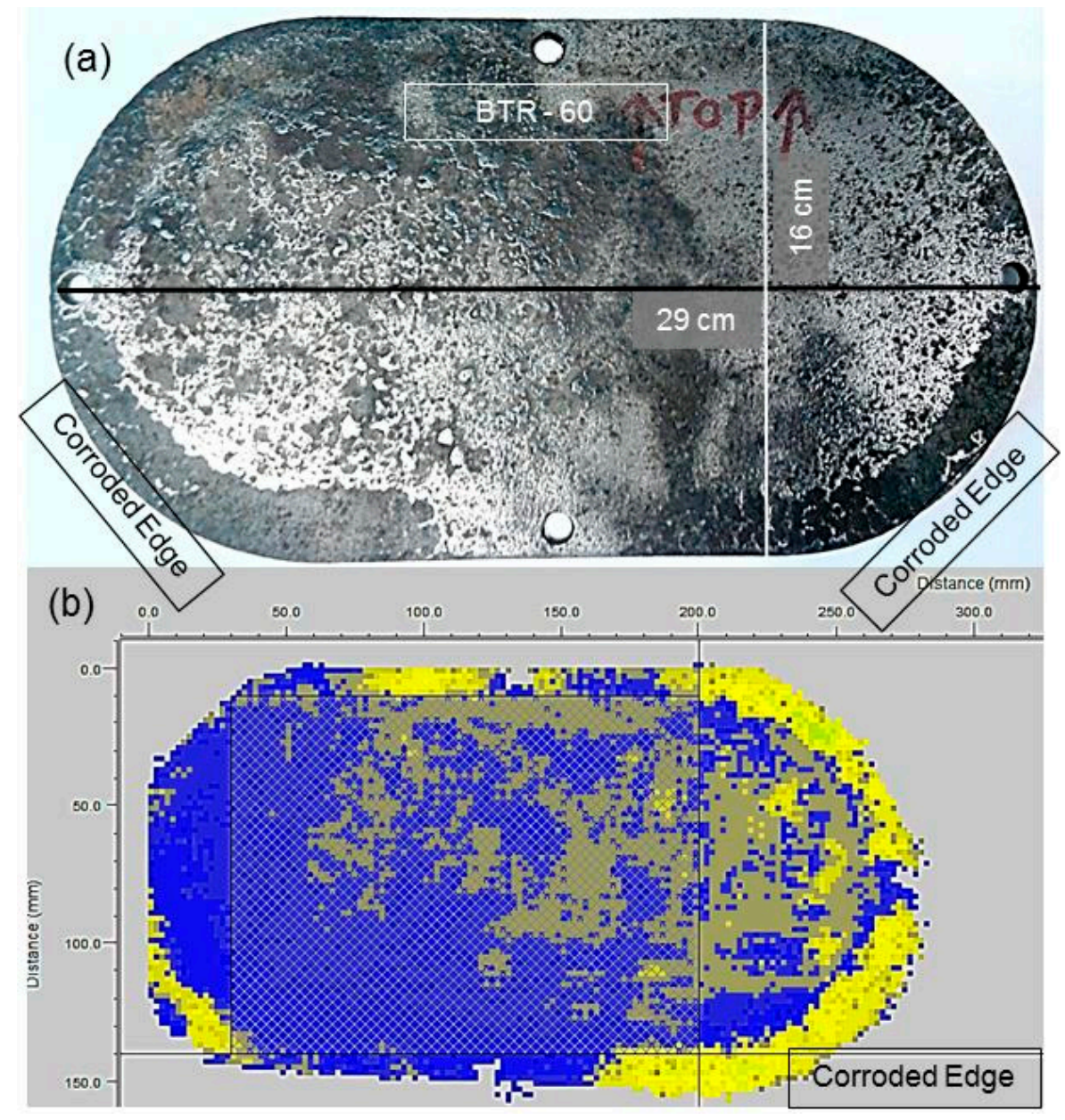

Figure 3. BTR-60 (a) sample's image and (b) ultrasonic scan.

Table 1. BT R-60 samples' scan results for 5 highest and lowest thicknesses.

\begin{tabular}{|c|c|c|c|}
\hline \multicolumn{4}{|c|}{$\begin{array}{l}\text { Russian BT-R } 60 \\
\text { Maximum Armour Thickness: } 14 \mathrm{~mm} \\
\text { Minimum Armour Thickness: } 5-7 \mathrm{~mm}\end{array}$} \\
\hline \multicolumn{4}{|c|}{$\begin{array}{c}\text { Sample's Dimension } \\
\text { Length: } 290 \mathrm{~mm} \text { Width: } 160 \mathrm{~mm}\end{array}$} \\
\hline S. No & \multicolumn{2}{|c|}{ Remaining Thicknesses in $\mathbf{m m}$} & No of Occurrences \\
\hline 1 & 5.00 & & 16 \\
\hline 2 & 5.10 & \multirow{9}{*}{ 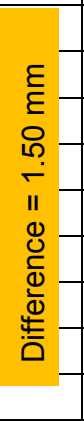 } & 46 \\
\hline 3 & 5.20 & & 123 \\
\hline 4 & 5.30 & & 322 \\
\hline 5 & 5.40 & & 420 \\
\hline 6 & 6.10 & & 17 \\
\hline 7 & 6.20 & & 5 \\
\hline 8 & 6.30 & & 3 \\
\hline 9 & 6.40 & & 4 \\
\hline 10 & 6.50 & & 3 \\
\hline
\end{tabular}




\subsection{The Environment}

Environment has a strong influence in the initiation and propagation of corrosion in metal structures; therefore study of the environments both inside and outside the shelters where the vehicles are stored has been conducted to relate corrosion activity within the context. It was observed that fluctuations in temperature and relative humidity inside the building are not viable for the structural health of the vehicles and presents a significant challenge for the vehicles' protection against structural deterioration sustainably.

\subsubsection{Environment inside the Shelter}

Inside the building, no measures are in place to control relative humidity during the year. However, temperature is kept between $18{ }^{\circ} \mathrm{C}$ to $22{ }^{\circ} \mathrm{C}$ during winter. It was observed that during the months from December-February, the relative humidity measured as high as $100 \%$. Analysis of the environment inside the shelter has pinpointed endless cycles of surface wetting and drying due to temperature and relative humidity variations.

The environmental variations in the shelter and atmospheric pollutants accumulated during operation plays a vital part in metal corrosion. Condensation happen on metal surface when temperature surpass $0{ }^{\circ} \mathrm{C}$, at relative humidity $\geqslant 80 \%$, this result in longer time of wetness (TOW) and ultimately cause atmospheric corrosion. In similar environmental conditions, a degree of corrosion is expected in the vehicles stationed inside the shelter [19-24].

\subsubsection{Environmental Analysis of Bovington}

Bovington is on the southwestern coast of England and is around seven miles from the English Channel. In Bovington, for 18 days of each month, considerable precipitation, fog, and rain are reported [25]. The relative humidity averages around $80 \%$ for most of the year, however in some months of the winter relative humidity reaches up to $100 \%$ [26]. The average high and low temperatures for the last 30 years $(1981-2010)$ were $14.03{ }^{\circ} \mathrm{C}$ and $8.11^{\circ} \mathrm{C}$, respectively, the average temperature fluctuations observed during 1981-2010 were between $7{ }^{\circ} \mathrm{C}$ to $22{ }^{\circ} \mathrm{C}$ in summers and $2{ }^{\circ} \mathrm{C}$ to $12{ }^{\circ} \mathrm{C}$ in winters [25,27].

Vehicles stationed outside the shelters in open environment are enduring a wide variety of environmental conditions, such as soils, rain water, condensation, temperatures fluctuations and relative humidity deviations. All these dynamics create an atmosphere for vehicles' corrosion.

\subsection{Paint System Failures and Surface Contaminations}

The most common and effective methods of protection against corrosion is the application of paint system on metal surfaces. However, there are conditions under which the paint system starts to degrade, although failures in the paint system do not cause structural failures, they are, however, linked indirectly to the promotion of component failures through corrosion. When the paint system starts to fail, it allows the permeation of moisture to the substrate, which as a result causes corrosion, one of the major causes of structural degradation. Paint system failure was observed in many vehicles, as shown in Figures 4 and 5. 


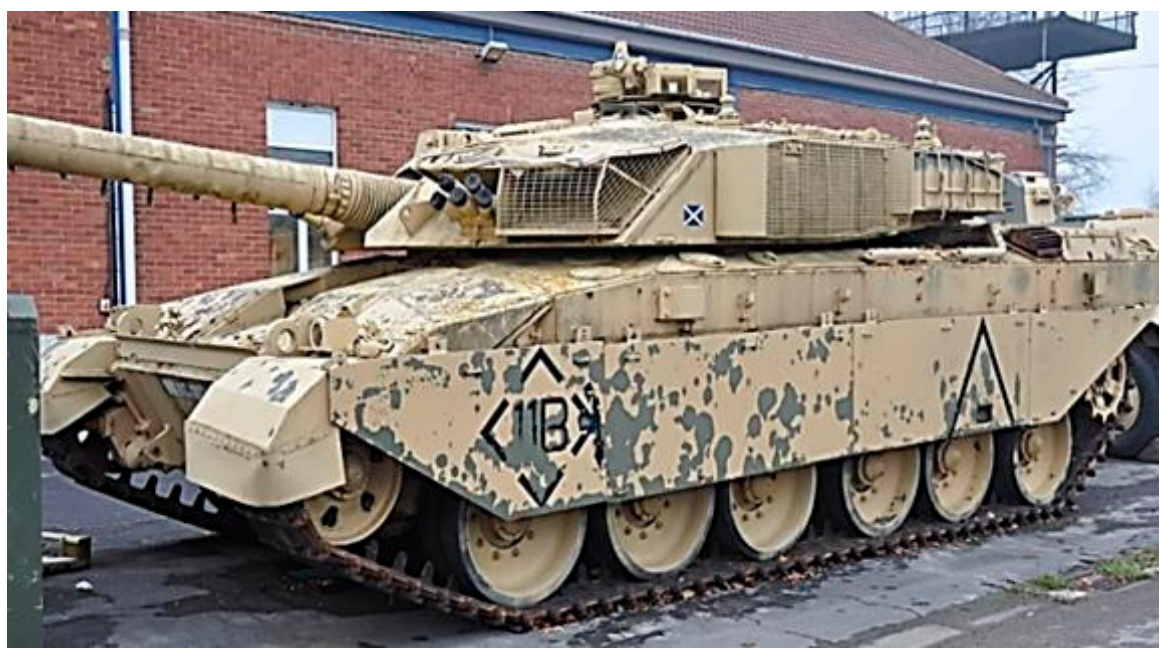

Figure 4. Challenger 1 failures in surface protection.

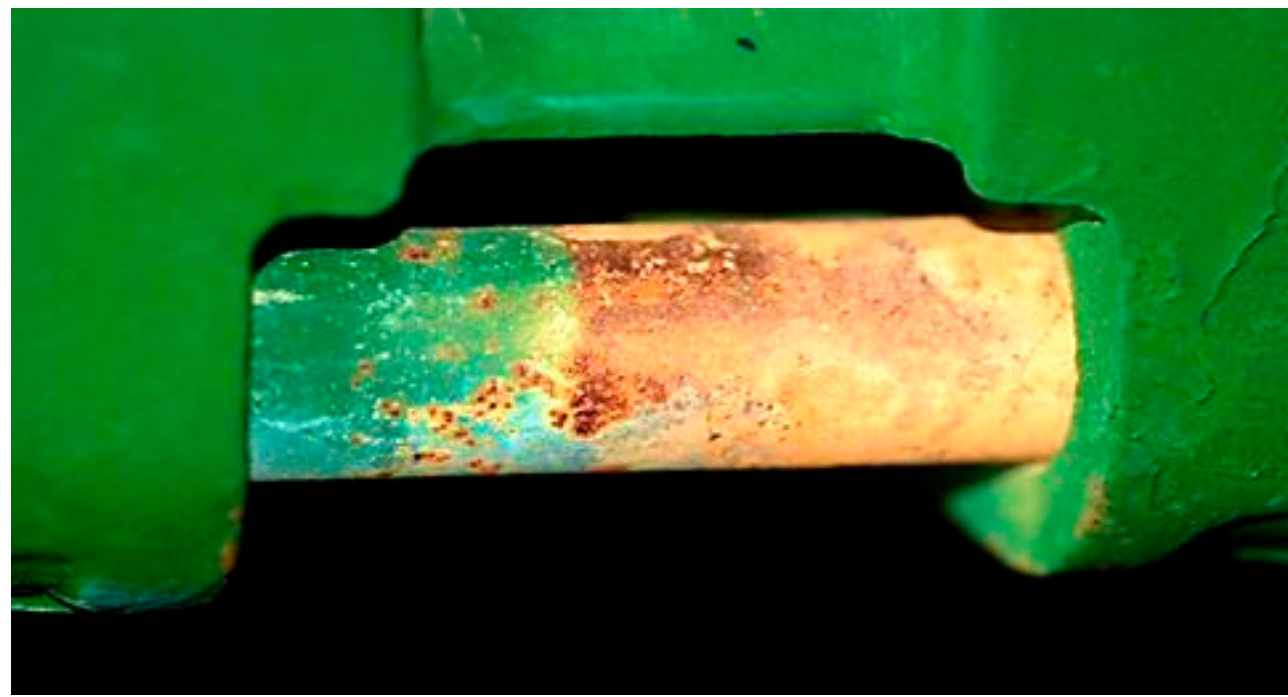

Figure 5. Centurion-stridsvagon 104 paint system following a corrosion attack.

It was identified that the phenomenon of corrosion was also influenced by the presence of surface contaminants and sub-surface defects such as slags, sulphide inclusions and corrosive pits. These factors alone and/or in combination were observed to be a serious issue. Sulphur, sodium, calcium and chlorine were identified on the vehicles' surfaces; these are classified as surface contaminants and result in accelerated corrosion, even at lower relative humidity [2].

\subsection{Component Failures}

Component failure is not only the cause of vehicles' malfunction but replacement is also a huge financial burden. Brief results of component failures from King Tiger and Tiger 1 are presented here; inadequate component replacement was also identified in this research [1].

\subsubsection{King Tiger}

Sd Kfz 182 Panzerkampfwagen VI Ausf B was the official German name for King Tiger and is also known as Tiger II. King Tiger was designed/Manufactured by Henschel \& Son during 1943-1945 in Nazi Germany. Its first place of action was Normandy in July 1944. The King Tiger was one of the 
most powerful tanks to be deployed during the 2nd World War; together with the Panther, it formed the lead of the German offensive in Ardennes [18,28].

The Gear Box of the King Tiger was disassembled after almost fifty years for corrosion investigation, as shown in Figure 6. The gearbox showed various types of corrosion in many of its components. Although the King Tiger does not operate anymore, it is, however, structurally degrading due to corrosion.

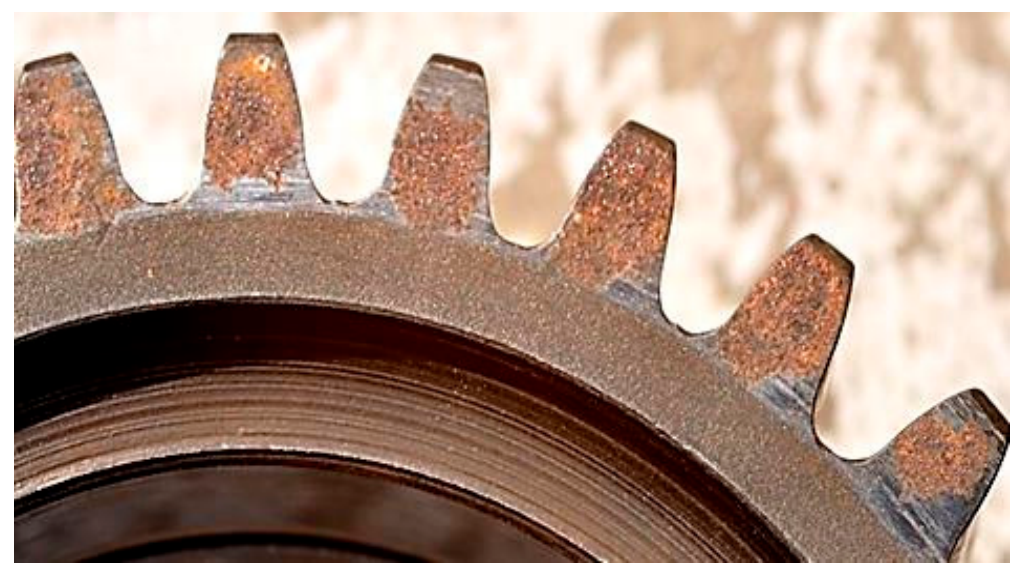

Figure 6. Corrosion problem in King Tiger's Gear Box Planet Gear.

\subsubsection{Tiger 1}

Tiger 1 was designed by Henschel \& Son in Nazi Germany. Panzerkampfwagen Tiger Ausf. E was the official German designation and it is commonly known as Tiger 1. Tiger 1 participated in the 2nd World War against the former USSR and Allied Forces. This vehicle was captured in Tunisia. Ostensibly, it is the last operating Tiger 1 in the World and is classified as a high value vehicle [18].

The Tiger 1 original and replacement engine pistons were evaluated for failures due to wear [1]. It was identified that the original pistons, which were manufactured during 2nd World War, had enhanced wear resistant properties. The replacement pistons were used as a substitute in the Tiger 1 engine, which failed catastrophically during normal operation. This failure could be attributed to inadequate material composition.

Tiger 1 operates occasionally; when it is stationary, there is the possibility of corrosion build-up in the engine, such an example is shown in Figure 7. Corrosive-wear has a detrimental impact on the engine performance in particular and on the Tiger 1 as a whole.

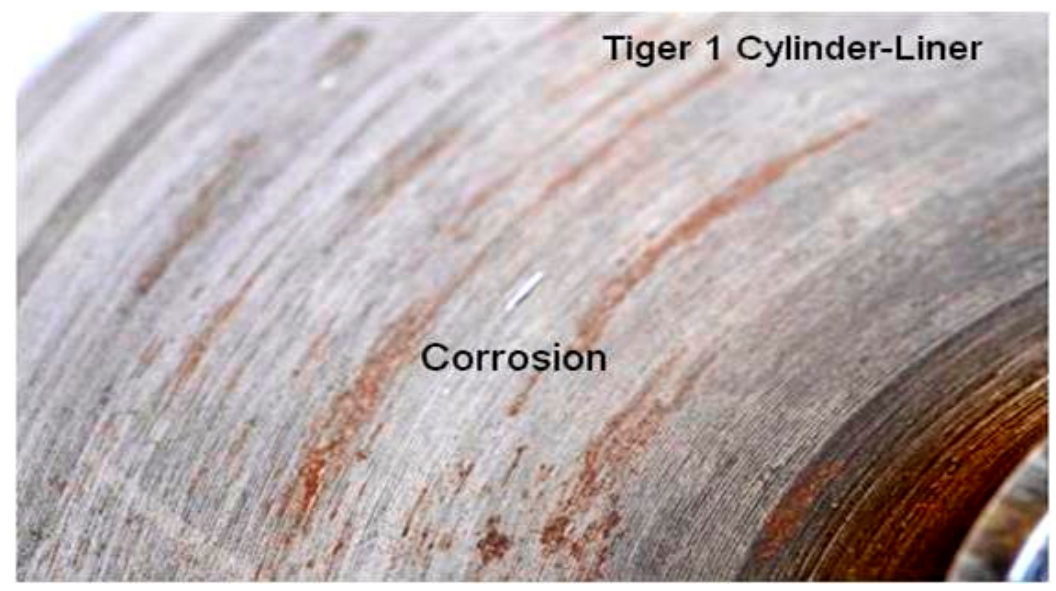

Figure 7. Tiger 1 corrosion build-up in the cylinder liner. 


\section{Research Impact}

This research has led to the initiation and development of condition monitoring and protection framework of large vehicles against structural deterioration. This is the first evidence-based research that has been performed in this field and is directly linked to the identification of prevailing failure mechanisms, measurement and analysis of the failures, development of a new sheltered facility incorporating relative humidity and temperature control, installation of the environmental monitoring system and in-situ corrosion condition monitoring framework. Building upon the theoretical advances in the development of Condition Health Monitoring Programme CHM-PM and its success in modelling a wide range of complex failure parameters has attracted increasing interests from defence, oil and gas, automotive and aerospace industries [8-15].

\subsection{Environmental Monitoring and Control}

Relative humidity and temperature monitoring sensors are now installed in the shelter at 10 locations, where the relative humidity and temperatures are constantly monitored. In addition to this, based upon the recommendations from this research, a new conservation facility shown in Figure 8 was recently built where temperature and relative humidity variations are kept to a minimum.

Keeping the occurrences of sharp rises and falls in relative humidity to a minimum, and ideally achieving an optimum level $(35 \%-45 \%)$, is an important factor with respect to keeping the vehicles protected. This can be achieved through better ventilation, dehumidification and air conditioning. Optimum scale of relative humidity and temperature will help mitigate corrosion, thus achieving extended life for large vehicles and effectively retarding environmental assisted damage.

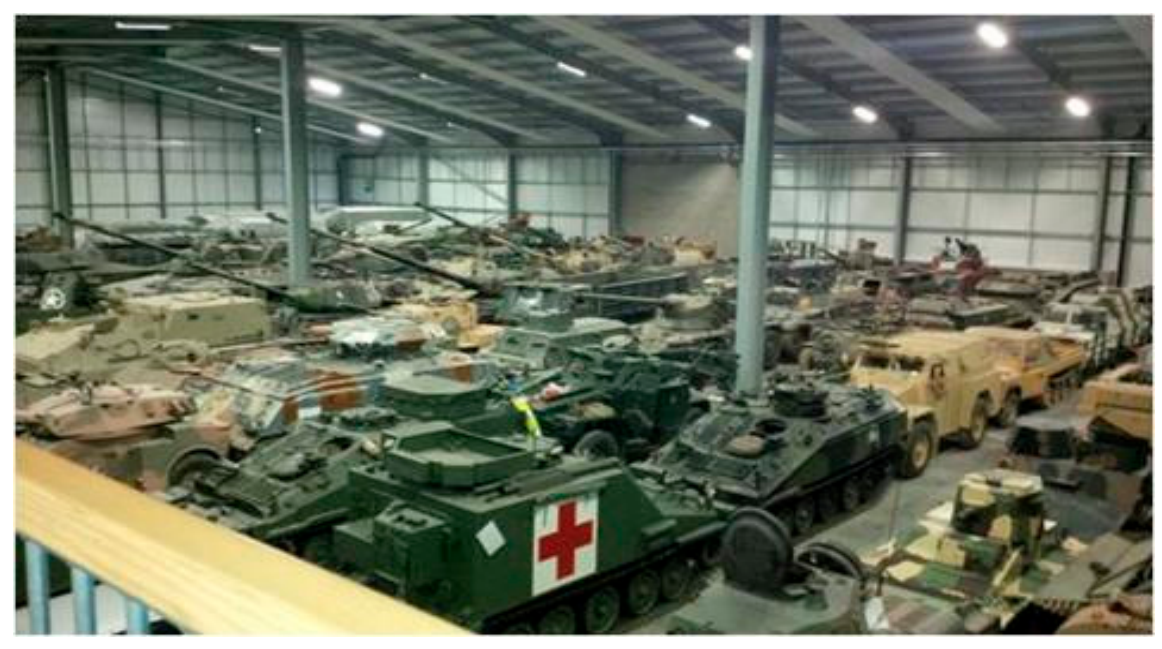

Figure 8. Collection of large vehicles that are now stored within a controlled environment in a new facility.

\subsection{In-Situ Corrosion Condition Monitoring}

A framework of in-situ condition corrosion monitoring based upon micro-linear polarisation resistors $[29,30]$ shown in Figure 9 is developed and installed on the vehicles. This framework is able to detect materials degradation through corrosion in large vehicles in its early stages. This is one of the novel systems to provide the opportunity to detect material degradation through corrosion in its early stages cost effectively and non-intrusively. It can be defined as condition-based maintenance (CBM), rather than scheduled-based maintenance (SBM), for corrosion mitigation before it becomes an unnecessary burden [31]. 
In the initial stage, sensors are installed on two valentine vehicles. One of the valentines is permanently stationed inside the shelter, whereas the other operates sporadically. Data are collected regularly in order to monitor the structural degradation of these two vehicles in real time. The data acquired enables delivery of a critical evaluation of the structural health, which is useful in terms of predicting corrosion failures. This framework provides an opportunity to protect the vehicles sustainably [32].

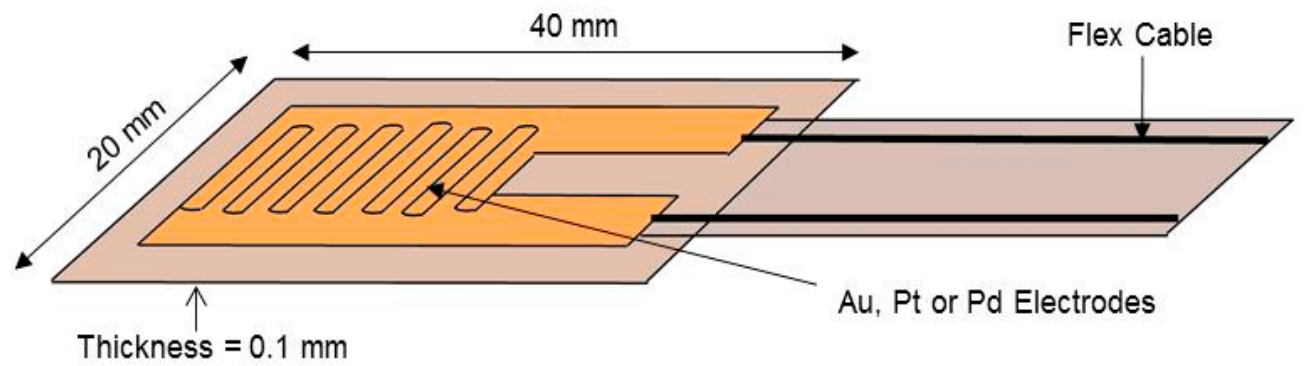

Figure 9. Three electrode corrosion sensors.

\subsection{Empirical Modelling of Paint System Failures}

One of the main reasons for paint system failures in large military vehicles is edge delamination or the gradual removal of paint system from the metal surface in time. This phenomenon is showed in Figure 10a. Research was conducted to develop a holistic model [12] for paint system failure predictions because of edge delamination as shown in Figure 10b. An advanced model to understand the cathodic delamination mechanism was developed. The model contains system and blocks, inside the blocks there are three interdependent parallel processes; Process of Cation Transport Modelling (Proc. CTM), Process of Delaminated Coating Modelling [Proc. DCM] and Process of Interfacial Propagation Modelling (Proc. IPM) as shown in Figure 10c. These processes represent (a) cation formation (b) reduction of oxygen and (c) mechanism of cation transportation. Every process in the model is a discrete algorithms with an ability of inter-communication. This communication is facilitated through duplex channels transmitting signals $r 2, r 3, r 5$ and $r 6$, which represents a discrete delamination parameter. The interdependency of several parallel processes makes the study and understanding of quantitative agreement among delamination parameters easier. The obtained results are in close agreement with the experimental data, its interpretation and numerical analyses which have been reported recently [12]. The proposed delamination prediction model will be a useful resource for future research.

Blistering is another reason why paint systems degrade in large vehicle that are in continuous operation in severe environmental conditions. An example of blistering in the paint system of a large vehicle is shown in Figure 11a. Research has been conducted to develop, model and predict initial paint system failure linked to blistering $[8,9,14]$. Both fracture mechanics classical theory approach and diffusion concepts have been incorporated through a generalised meso-mechanics modelling techniques to analyse blister initiation and propagation in two distinct stages. Diffusion concept have been deployed to represent the transport of corrosive species towards the interface of paint system and substrate, and facture mechanics concept to show blister growth in the form of circular crack propagation. A simple criterion is identified by using a developed interfacial toughness equation, which however does not include blister propagation on wider scale. The model has been validated using experimental methods showing a good qualitative agreement between the two.

The previously mentioned blistering model was further modified in order to predict paint system failures due to unstable propagation of circular blisters in the form of worm-like patterns as a result of the development of compression and diffusion induced stress in harsh environments, as shown in Figure 12a. Paint system de-bonds from the substrate due to sufficiently large delamination, giving rise to blister, which consecutively induces the driving force on crack tip at interface. The crack tip 
driving force decides the interface toughness, higher driving force account for low interface toughness and vice versa. The predictive model shown in Figure $12 \mathrm{~b}$ presents non-axisymmetric perturbation of blister in to branching, which eventually results in worm-like pattern. The model was validated using detailed experimental study on a palladium-coated steel substrate, which allows the visualisation of delamination of paint system under the influence of both compression and diffusion of species. The investigation suggests that non-axisymmetric instabilities would develop at the crack tip during the propagation of blister, which eventually results in worm-like patterns, the patterns often observed in the delamination of thin paint systems.
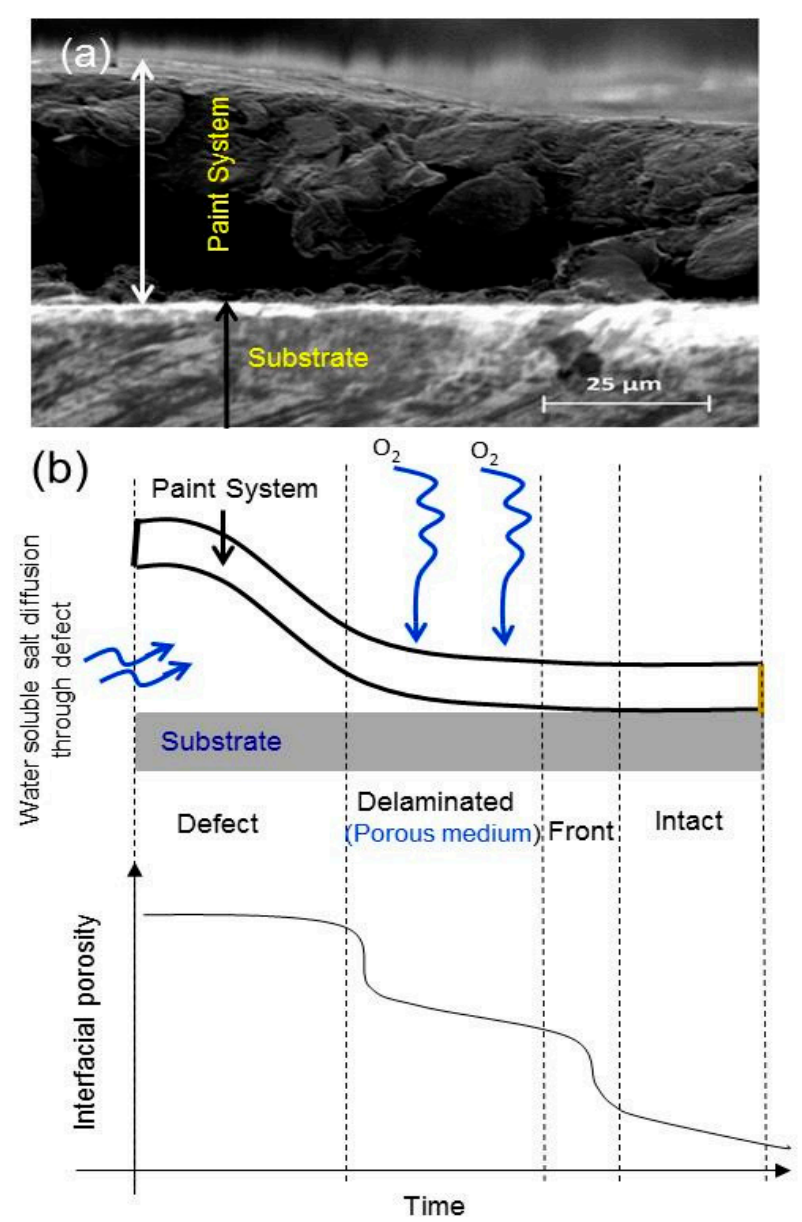

(c)

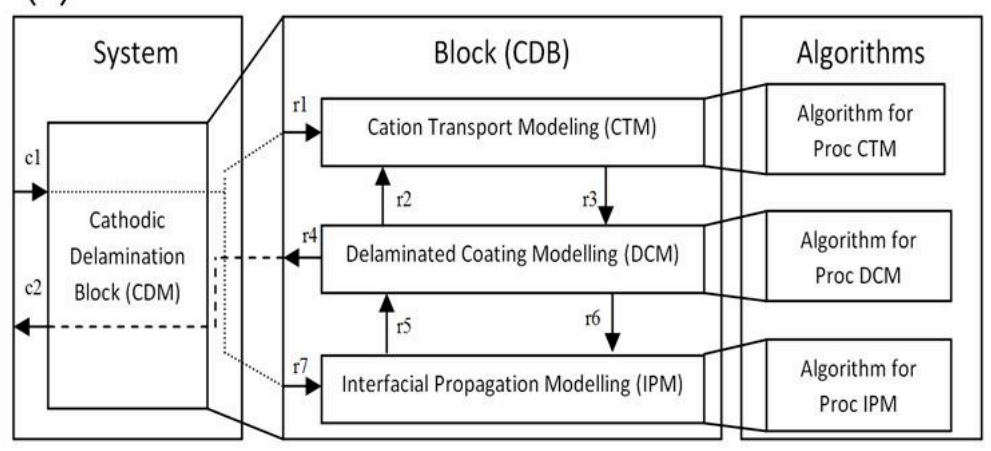

Figure 10. (a) Process of actual paint system failure. (b) Schematic representation of paint system failure. (c) Representation of cathodic delamination mechanism-modelling methodology. 


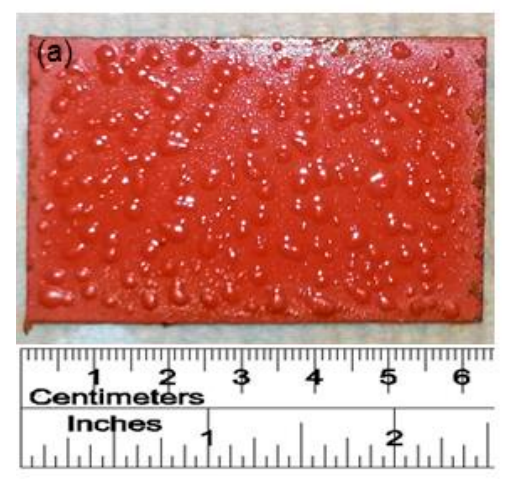

(b)

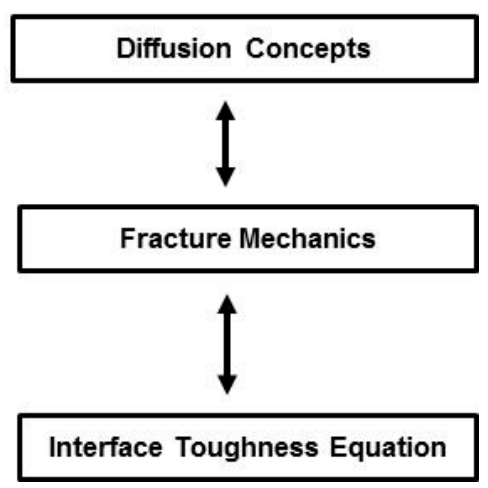

Figure 11. (a) Blisters on steel sample; and (b) modelling methodology for blistering.

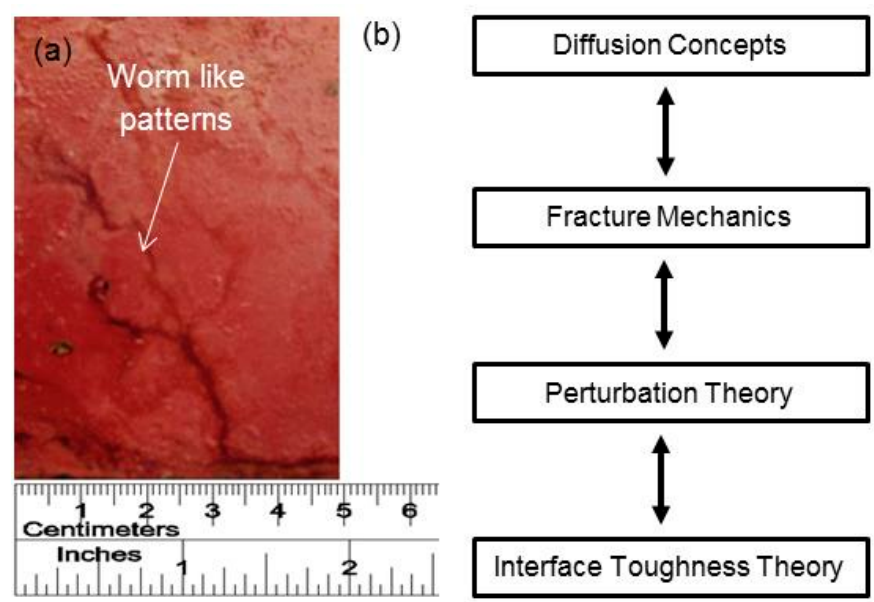

Figure 12. (a) Sample showing the propagation of blister in to worm like pattern under increasing resultant coupling stress (residual stress coupled with diffusion induced stress). (b) Modelling methodology for unstable blister propagation.

\subsection{Public Engagement}

Results from this research aims to extend the life of these high value vehicles through sustainable conservation methods. This could mean that the general public and future generations will be able to enjoy British and other engineering legacies for a longer time.

Public interaction includes a large YouTube following (over one million) about the Tiger Tank (2nd World War, German made, restored in Bovington) with concerns relating to durability and public value of experiencing high value vehicles in operation. Tiger 1 is the last working example and demonstrated during displays at Bovington.

\subsection{Further Research and Grants}

This project has attracted immense attention from academia and industry within the United Kingdom and across Europe. The research also has been perceived by the general public as a high quality collaborative study, which has been focusing on the protection of high value vehicles with significant cultural and historic biographies in Great Britain and across the World.

Large vehicles that are currently used by industries, defence and the public sector display the same modes of failures over a specific time. Through an understanding of this research, there will be an opportunity to phase-out degradation problems that may not be predictable through conventional methods. 
Findings from this research helped to secure further grants including $£ 2,560,600$ for new conservation facility at Bovington, $£ 20,000$ for research into flow assisted corrosion failures, $£ 23,000$ for in-situ corrosion condition monitoring and $£ 24,000$ for corrosion health monitoring using wireless sensor technologies.

\section{Conclusions}

The outcomes from this research indicate wide ranging contributions in-terms of identifying failure mechanisms, finding solutions to the increasing problems in large vehicles, and implementing an optimised approach of protecting and sustaining large vehicles. Although the past working environment and operating duration of the vehicles is very complex to track, the damaged caused due to corrosion has been recorded. Figure 1 displays the magnitude of corrosion and the possible consequences if preventative measures are not taken.

During this research, factors linked directly or indirectly to structural failures such as environment, component and paint-system failures were analysed. It was revealed that environments outside and inside shelters were not sustainable for the longevity of the vehicles. Variations in environmental parameters play a pivotal role in material degradation.

Paint-system failures were found to be linked to structural damage and a major concern for vehicles' durability. Vehicles are exposed to the outside environment from time to time, which may result in the accumulation of surface contaminants. In the likelihood of an inadequate paint-system, atmospheric corrosion could occur, even when vehicles are stationed inside the shelters.

Close proximity of Bovington to the English Channel results in rain, wind, temperature, relative humidity variations and airborne salts contents. For vehicles parked outside the shelters, it is important that adequate paints system is in place on the surfaces for protection against such conditions.

The development of the framework to monitor temperature and relative humidity in shelters as a result of this research provides an opportunity to keep the environmental variation to a minimum when needed. Through better environmental control systems and condition monitoring techniques, the durability and longevity of the large vehicles can be enhanced.

The research helped to identify component failures attributed to corrosion, inadequate material composition and design.

Data obtained as a result of $i n$-situ corrosion condition monitoring technique are important in the context of monitoring structural reliability in real time. This is a condition-based approach rather than a scheduled-based approach. This framework also provides the opportunity to look into materials behaviour under certain environmental conditions.

The proposed empirical model provides a foundation for continued research within paint-systems failures.

Through a five-fold research pattern of identifying, measuring, analysing, monitoring and protecting large vehicles against structural failures, a framework of an optimised approach to protect and sustain large vehicles against structural failures is initiated.

Apart from contributing to research community and museums, this research has shown its impact on various sections of society, like the automotive industry. This research provides a model to protect and sustain large historic vehicles as valuable assets for the current and future generations.

Acknowledgments: NanoCorr, Energy \& Modelling Research Group at Bournemouth University acknowledges in kind support provided by Advanced Technology Centre BAE systems UK, The Tank Museum at Bovington UK and Analatom USA. The authors also acknowledge financial support through match funding by the Defence Science and Technology Laboratory UK and Bournemouth University.

Author Contributions: Adil Saeed started the initial research in large vehicles. In this article, Adil Saeed has contributed to research in the corrosion damage evaluation, component failures identification, paint-system failures and environmental analysis. Main H. Nazir is currently contributing to research in paint system failures and condition monitoring techniques. In this article, he has contributed towards research in the in-situ condition monitoring and the development of the empirical model for paint-system failures. Zulfiqar A Khan (Associate 
Professor) has led the successful completion of a recent project in corrosion of large vehicles as lead supervisor. He is currently leading a substantive research portfolio in corrosion, which is funded by major industrial partners and international higher education institutions (HEIs). He has made key contributions to the ideas of scientific approach and development of methodologies in corrosion.

Conflicts of Interest: The authors declare no conflict of interest.

\section{References}

1. Saeed, A.; Khan, A.Z.; Hadfield, M.; Davies, S. Material characterization and real-time wear evaluation of pistons and cylinder liners of the tiger 131 military tank. Tribol. Trans. 2013, 56, 637-644. [CrossRef]

2. Saeed, A.; Khan, Z.; Montgomery, E. Corrosion Damage Analysis and material Characterization of Sherman and Centaur-The Historic Military Tanks. Mater. Perform. Charact. 2013, 2, 30-44. [CrossRef]

3. Wilton-Smith, K.; Khan, Z.; Saeed, A.; Hadfield, M. Accelerated corrosion tests of waste-gated turbocharger's adjustable and fixed end links. In Proceedings to the International Conference on High Performance and Optimum Design of Structures and Materials, Ostend, Belgium, 9-11 June 2014.

4. Saeed, A.; Khan, Z.; Garland, N.; Smith, R. Material characterisation to understand various modes of corrosion failures in large military vehicles of historical importance. In Proceedings of the Fifth International Conference on Computational Methods and Experiments in Materials Characterisation, Kos, Greece, 13-15 June 2011.

5. Saeed, A.; Khan, Z.; Clark, M.; Nel, M.; Smith, R. Non-destructive material characterisation and material loss evaluation in large historic military vehicles. Insight Non-Destr. Test. Cond. Monit. 2011, 53, 382-386. [CrossRef]

6. Khan, A.Z.; Grover, M.; Nazir, H.M. The Implications of Wet and Dry Turning on the Surface Quality of EN8 Steel. Trans. Eng. Technol. 2015. [CrossRef]

7. Khan, A.Z.; Pashaei, P.; Bajwa, S.R.; Nazir, H.M.; Camak, M. Fabrication and characterisation of electrodeposited and magnetron sputtered thin films. Int. J. Comput. Methods Exp. Meas. 2015. in press.

8. Nazir, H.M.; Khan, A.Z.; Stokes, K. A unified mathematical modelling and simulation for cathodic blistering mechanism incorporating diffusion and fracture mechanics concepts. J. Adhes. Sci. Technol. 2015, 29, 1200-1228. [CrossRef]

9. Nazir, H.M.; Khan, A.Z.; Stokes, K. Optimisation of interface roughness and coating thickness to maximise coating-substrate adhesion-a failure prediction and reliability assessment modelling. J. Adhes. Sci. Technol. 2015, 29, 1415-1445. [CrossRef]

10. Nazir, H.M.; Khan, A.Z.; Stokes, K. Modelling of metal-coating delamination incorporating variable environmental parameters. J. Adhes. Sci. Technol. 2014, 29, 392-423. [CrossRef]

11. Nazir, H.K.; Khan, A.Z.; Stokes, K. Maximising the interfacial toughness of thin coatings and substrate through optimisation of defined parameters. Int. J. Comput. Methods Exp. Meas. 2015. in press.

12. Nazir, H.M.; Khan, A.Z.; Stokes, K. A holistic mathematical modelling and simulation for cathodic delamination mechanism-A novel and an efficient approach. J. Adhes. Sci. Technol. 2015, 29, 2475-2513. [CrossRef]

13. Nazir, H.M.; Khan, A.Z.; Saeed, A.; Stokes, K. Modelling the Effect of Residual and Diffusion induced Stresses on Corrosion at the Interface of Coating and Substrate. Corrosion 2015. in press. [CrossRef]

14. Nazir, H.M.; Khan, A.Z.; Saeed, A.; Stokes, K. A model for cathodic blister growth in coating degradation using mesomechanics approach. Mater. Corros. 2015. [CrossRef]

15. Nazir, H.M.; Khan, A.Z.; Stokes, K. The propagation and axisymmetric stability of circular, defect driven coating delamination under the influence of compression and diffusion induced stress. Intl. J. Eng. Fract. Mech. 2015. submitted.

16. Drury, C.J. Ultrasonic Flaw Detection for Technicians, 3rd ed.; Silverwing Ltd.: Swansea, UK, 2004.

17. Drinkwater, W.B.; Wilcox, D.P. Ultrasonic Arrays for Non-Destructive Evaluation: A Review. NDT E Int. 2006, 39, 525-541. [CrossRef]

18. Jackson, R. Tanks and Armoured Fighting Vehicles; Parragon: Bath, UK, 2007.

19. Cai, P.J.; Lyon, B.S. A mechanistic study of initial atmospheric corrosion kinetics using electrical resistance sensors. Corros. Sci. 2005, 47, 2956-2973. [CrossRef]

20. Schweitzer, A.P. Fundamentals of Corrosion: Mechanisms, Causes, and Preventative Method; CRC: Boca Raton, FL, USA, 2010. 
21. ISO Standards. Corrosion of Metals and Alloys-Corrosivity of Atmospheres-Classification, Determination and Estimation; International Organization for Standards: Geneve, Switzerland, 1992; p. 15.

22. Lyon, B.S. Corrosion of Carbon and Low Alloy Steels, Shreir's Corrosion; Tony, J.A.R., Ed.; Elsevier: Oxford, UK, 2010; pp. 1693-1736.

23. Landolfo, R.; Cascini, L.; Portioli, F. Modeling of metal structure corrosion damage: A state of the art report. Sustainability 2010, 2, 2163-2175. [CrossRef]

24. Montgomery, L.E.; Calle, M.L.; Curran, C.J.; Kolody, R.M. Timescale correlation between marine atmospheric exposure and accelerated corrosion testing. In Proceedings of the NAC-International Corrosion Conference, Houston, TX, USA, 13-17 March 2011.

25. Wunderground. Available online: http://www.wunderground.com/weatherstation/WXDailyHistory.asp? ID=IDORSETB5 (accessed on 21 November 2011).

26. Metoffice. Available online: http://www.metoffice.gov.uk/climate/uk/stationdata/hurndata.txt (accessed on 21 November 2011).

27. Dorsetforyou.com. Climate data for Weymouth, England (1981-2010). Available online: http://webapps-wpbc.dorsetforyou.com/apps/weather/annualreport.asp (accessed on 10 January 2012).

28. The Tank Museum. King Tiger-Sd Kfz 182 Panzerkampfwagen VI Ausf B. Available online: http://www.tankmuseum.org/ixbin/indexplus?_IXSS_=_IXMENU_\%3d\%26ALL\%3dking\%2btiger\%26_ IXACTION_\%3dsummary\%26\%252asform\%3d\%252fsearch_form (accessed on 27 July 2012).

29. Brown, D.; Darr, D.; Morse, J.; Laskowski, B. Real-Time Corrosion Monitoring of Aircraft Structures with Prognostic Applications. In Proceedings of the Annual Conference of the Prognostics and Health Management Society, Minneapolis, MN, USA, 23-27 Septmber 2012.

30. Brown, D.; Darr, D.; Morse, J.; Laskowski, B. Theoretical and Experimental Evaluation of a Real-Time Corrosion Monitoring System for Measuring Pitting in Aircraft Structures. In Proceedings of the First European Conference of the Prognostics and Health Management Society, Dresden, Germany, 3-5 June 2012; Volume 3, pp. 1-9.

31. Brown, D.; Darr, D.; Morse, J.; Betti, R.; Laskowski, B. Advanced Sensing, Degradation Detection, Diagnostic and Prognostic Capabilities for Structural Health Management. In Proceedings of the Conference on Nondestructive Characterization for Composite Materials, Aerospace Engineering, Civil Infrastructure and Homeland Security, San Diego, CA, USA, 26 April 2012.

32. Liu, H.Z.; Lee, Y.J. A Method for Development of Ecomuseums in Taiwan. Sustainability 2015, 7, 13249-13269. [CrossRef]

(C) 2015 by the authors; licensee MDPI, Basel, Switzerland. This article is an open access article distributed under the terms and conditions of the Creative Commons by Attribution (CC-BY) license (http://creativecommons.org/licenses/by/4.0/). 